greatest faith. The MAYon replied on behalf of the corporation. The health of the guests was proposed by Alderman C. W. Buckley, M.D., and the reply was entrusted to Sir William Willcox and Dr. R. A. Fleming. The toast of "The Press" was proposed in an excellent speech by Lord Hartington. Lastly, "Success to Other Municipalities" (many of which were represented at the dinner by their mayors) was submitted by Alderman MrLL and replied to by the Lord Mayor of ShefFiedd.

\section{The Baths of Buxton.}

On the following morning the medical visitors, under the guidance of Dr. Buckley, were able to examine the methods of treatment carried out in the bathing establishments, and many of them enjoyed a bathe in the blue water of the large swimming pool: Their examination was aided by a booklet on the mineral springs of Buxton, giving a brief account of the action and uses of the thermal and chalybeate waters, written by a committee of the Research Society of the Devonshire Hospital.*

The baths are in two buildings, occupying sites at the west and east ends of the Crescent. The former-those opened publicly on the afternoon of May 17th-are the "natural baths"; they possess a very complete modern equipment, installed at a cost of $£ 20,000$. Most of the principal springs rise in this building, and the water flows continuously through the baths, so that the patient is immersed in a stream of running water effervescent with nitrogen. The combined output of the wells is about half a million gallons a day. The water rises at a uniform temperature of $82^{\circ} \mathrm{F}$., which is very pleasant for swimming. Onder medical direction the tonic effect of the cool bath is re-enforced or prepared for by hot-water douching, friction, massage, and exercise, as occasion requires.

The handbook indicates the composition of the two Buxton waters, the principal methods of external application, including the local douche-massage, and the diseases suitable for treatment at this spa.

\section{ANALYTIC PSYCHOLOGY.}

Lectures by Dr. C. G. Jung of Zürich.

$$
\text { (From a Correspondent.) }
$$

[Concluded from p. 879.]

\section{II.}

In the second of his lectures, given in London (on May 13th), Dr. C. G. Jung of Ziirich said that, through the analysis and interpretation of dreams, an attempt was made to understand the tendencies of the unconscious. To say "tendencies of the unconscious" sounded almost like a personification of the unconscious, and as though the unconscious were an autonomous factor centred in itself. But from a scientific point of view the unconscious was simply a quality of various scientific phenomena. It was not possible even to say what these phenomena were, or whether they were usually unconscious or not, for anything might and could become unconscious. Anything forgotten, anything from which attention was diverted, might become unconscious. Anything in general that lost a certain energic intensity became subliminal. When the many subliminal sense perceptions were added to lost memories, the many subliminal and half-subliminal thoughts and feelings, then some idea could be obtained of the upper layers of the unconscious. This was the material dealt with in practical analysis. Some of the unconscious contents had been actively repressed by the conscious. Through a more or less wilful act of diversion of attention, and through an active resistance to them, they had been expelled from consciousness. This was a regular occurrence in hysteria. It was the beginning of that dissociation of the personality which was a conspicuous feature of a serious case of hysteria. Although

* The Natural Thermal and Chalybeate Waters of Buxton. Buxton: Derbyshire Printing Co., Ltd. 1924. 1s. repressions occurred in a more or less normal mentality, the absolute loss of repressed memories was pathological, even in a normal mind. Repression, or rather suppression, was in itself a normal process used every day. If man were unable to repress the contents of consciousness, he would not be able to divert his attention or change the subject. But if they could not be recalled it might be a case of repression. If so there must be some conscious interest that made forgetting desirable. But there was such a thing as simple forgetting, as happened when the conscious contents were loosely connected. Repression was an artificial loss of memory-an auto-hypnotic amnesia.

It was not justifiable to assume that the unconscious consisted only or chiefly of repressed materials. If that were so it would only be necessary to remove certain conscious resistances to make the lost memories conscious, and some had suggested that the unconscious would then be completely deflated and heard of no more.

The same thing that had happened to the sex theory had happened to the theory of repression: it had been exaggerated out of all proportion. Freud had never taken into account the fact that important contents could disappear from consciousness without repression. They sometimes vanished automatically, much to the individual's distress. Any conscious content related to the underlying unconscious content might disappear suddenly, not by repression from above, but by attraction from below. If the unconscious consisted only of repressions, creative activity in the unconscious could not be conceived. It was through such a riew that the absurd theory had been put forward that religion and art were nothing but substitutes for infantile sexuality. In such a view Westminster Abbey was nothing but a repressed infantile longing for a bush-shelter!

Experience showed every day that the unconscious was a living and therefore creative process, and needed no pathological repression in order to release its creative function. Neuroses and morbidity were proportionate to the degree of genuine repression, and if all the beauty and grandeur of the works of man were only poor substitutes for what was infantile and primitive, the Freudian creed itself might be regarded in the same way. A neurotic was a sick man, and disease never promoted creative work.

It was not known how consciousness arose from unconsciousness. But there were two ways in which it could be seen to come about-in moments of high emotional tension, and in a contemplative condition, where representations moved like dream-images. A concentration of energy arising from an external or internal stimulus brought about consciousness, and such moments were a kind of revelation. Early infantile memories contained the traces of such sudden flares into consciousness.

He divided the unconscious into two parts. The personal unconscious contained everything subliminal that had been acquired by the individual consciously or unconsciously. These contents had an unmistakably personal stamp. But other contents were to be found which were often enormously strange to the individual. Such materials were frequently discovered in insanity, but they also occurred occasionally in the dreams of normal people. The unconscious material furnished by the analysis of a neurotic person or a pativit suffering from dementia praecox varied enormously. With the neurotic all was personal. In sanity the personal memories disappeared behind powerful collective representations. The mad man heard the voice of Gơd speaking to him. His vision showed him cosmic revelations; it was as though a veil had been drawn away from a world of hitherto concealed ideas and emotions. He began to talk of ghosts and demons, witchcraft, and secret magical persecutions, things belonging to the world of the primitive mind which was deeply unconscious in normal cultured modern persons, but which rose to the surface when something fatal happened to the conscious: This was the collective unconscious-collective because it was not an individual acquisition but was the functioning of the inherited brain structure, which, in general, is the same in all human beings, and in certain respects the same in all mammals. The inherited brain was the result of the ancestral psychic life. It consisted of the structural deposits of the psychic 
activities repeated innumerable times in the lives of our ancestors.

The individual unconscious was a superstructure upon the collective unconscious, and usually the influence of the latter was subtle and almost imperceptible. Only at times did it appear in dreams, and whenever it did it produced strange and marvellous dreams remarkable for their beauty or for their demoniacal horror, or for their enigmatic wisdom. People often hid such dreams as precious secrets; they were right in doing so, for they had an enormous importance for the individual psychic balance. Even though they were beyond the individual's mental range, and might never be altogether understood, they stood out for him as spiritual landmarks. It was hopeless to interpret such dreams reductively, as their real value and meaning lay in themselves. They were spiritual experiences that defied any attempt at rationalization. Such dreams arose from a deeper level than the ordinary every-night dream. In the Freudian doctrine, until very recently the collective unconscious had had no place. But in treating the problems of the individual mind the fact that it consisted largely of inherited elements must not be ignored. It was only heredity that could explain the astonishing analogies between mythology on the one hand and dreams and delusions on the other. It was true that the collective unconscious became apparent only when some unusual condition released its independent activity. To sane people these veiled intimations of eternal things were in almost grotesque contrast to the personal dreams of those who were frittering their lives away in the arid futilities of routine work or amusement. When the way of life forked before us, and we were confronted with the irrevocable choice of our way, and also in moments of great danger, these superpersonal figures of our own fate came to tap us gently on the shoulder. Such a dream from the collective unconscious was a memento mori.

The problem of children was adaptation to a very personal reality. Above all else they added consciousness. The persistence of their connexion with primordial unconsciousness would be a formidable obstacle to the evolution of consciousness. Beyond middle life the significance of the collective unconscious was a very different matter. Our psychology varied with our age. A child must not be treated as an adult. The attention of children should not be called to the unconscious, for it was easy to rouse an unwholesome curiosity or create an abnormal precocity. When difficult children had to be treated analytic psychology should be kept in abeyance, for simplicity and common sense were what the child needed. Analytic knowledge ought to serve the teacher's attitude, because children were very sensitive to their teacher's shortcomings. They knew intuitively the false from the true. Therefore the teacher should watch his own psychic condition, so that he could be sure of the source of the trouble when things went wrong with the child in his care. He himself might be the unconscious cause of evil. There were people-analysts as well as teachers and parents-who thought they had the right to behave as they liked, and that the child must adapt to them much as he must adapt to the life of the world. Such people were convinced at heart (not openly) that the only thing that mattered was material success, and that the only convincing moral limitations were those of the penal code. It would be vain to expect such persons to exercise psychological introspection as a moral obligation. But the teacher should know what his convictions were, and stand for them. Upon a man's own philosophy, conscious or unconscious, depended his ultimate interpretation of facts. It was wise to be as clear as possible about subjective principles. Psychology had a broader application, educationally, to children than this, but he had only been able to touch on a few points. Those were most fitted to lead the child's mind and spirit to more consciousness and responsibility who had themselves attained the full stature of intellectual and moral manhood or womanhood-who in the correct sense of the word had passed the stage of driven instinctive mechanisms and had become individuals. That (said Dr. Jung, in conclusion) was a study and a labour which no one need imagine would easily be brought to an end.

\section{9reland.}

\section{Demobilization of Medical Officers in the}

Irish Free State.

THe following correspondence has taken place between the Ministry of Defence and the Irish Medical Secretary with regard to the demobilization grant, paid to officers in the Irish Free State, from which medical officers alone were excluded. The reply from the Ministry of Defence will be much appreciated by the medical officers affected:

"I wish to bring to your notice the unfair treatment accorded to medical officers of the National Army who have been demobllized as per S.D.m. No 13 . All such officers, with a few exceptions, have been informed that they are not eligible to receive the document specifies that in view of the proposed reorganization of the Army certain officers were to be demobilized, and that these officers would then be eligible for grants which amounted to three months' full pay plus \&5 towards the purchase of civilian clothing. There was no mention in the order of any particular group of officers or of any special service being excluded from these benefits, and every medical officer reading
the document was under the distinct impression that medical officers were just as eligible to share in the grants as any others. According to a statement of the Chief Pay and Accounts Officer, dervice prior to 7 th, 1924, only those officers with twelve months months' salary grant and not eligible for the civilian clothing grant I was informed that this letter, though dated February 7th, 1924, was not comimunicated to medical officers until this present month. Mention has been made of the fact that medical officers had signed a contract terminating on March 31st, whereas line officers had not; but the contract only gave the medical officers the doubtful satisfaction that they could not be held for service after the specified date, though reserving to the Army they thought fit.

"At any rate the general body of medical officers were under the impression that they were included in the terms of these grants and there was neither a Defence nor General Routine Order specifying that such was not the case, and the recent action of the Finance Authorities in excluding medical officers does not appear to have the official sanction of either the Minister of Defence or the Adjutant-General under whose control the medical services are. Irishmen who joined the commissioned ranks of the R.A.M.C. during the great war signed a twelve months' contract and received a gratuity on its termination if they wished to leave. In addition, they received a higher rate of pay or their services.

"At the present time civil employment in the medical profession is by no means easy to obtain, which makes the action of the Army authorities-in throwing so many medical men into
civil life without the smallest compensation-a very great hardship. Most of the demobilized medical officers joined the Free State Army Medical Service immediately after being qualified and were thus debarred from doing the usual post-graduate work to fit them for general practice. Moreover, the practice a doctor meets with in the army is very limited in scope. In the circumstances a gratuity for demobilized medical officers would be of very great help to them in order that they might be in a position to acquire a more general and practical knowledge of their profession-thus placing them in a position to compete with their better equipped colleagues, especially in times when there is a great scarcity of medical employment.

$$
\text { (Sgd.) T. Hennessy, }
$$

To this letter the Ministry of Defence has replied : "With reference to your letter of the 15th ultimo, I am
directed by the Minister of Defence to inform you that arrange-
ments are being made for the issue of demobilitation ments are being made for the issue of demobilization pay to services in the Army terminated prior to March 31st and whose

\section{Motor Taxes in the Free State.}

The Irish Medical Secretary has recently written to the University members of An Dail asking that they should make representations to the Minister of Finance with regard to the remission, reduction, or modification of the motor car tax as it affects medical practitioners generally, but especially those engaged in the Poor Law medical services. The following were some of the reasons put forward why dispensary doctors are entitled to special consideration :

1. The salaries paid Poor Law or dispensary medical officer are generally less than the travelling expenses which they receive or their public duties.

2. If a dispensary doctor used horse power for his work he would earn the same salary and be exempt from motor tax.

3. A doctor uses a motor car almost entirely for the reasons : in urgent cases. (b) When illness is epidemic or prevalent the 